\title{
Development of orange flavour emulsion
}

\section{Saifullah and M. G. Aziz}

Department of Food Technology and Rural Industries, Bangladesh Agricultural University, Mymensingh -2202, Bangladesh, Email: saif.emon04@gmail.com

\begin{abstract}
The study was concerned with development of orange flavor emulsion by homogenizing method. Different gum concentration and number of passes were used during emulsion formation. Three different concentration of Gum Arabic (10\%, 15\% and 20\%) and 4, 6 and 8 numbers of passes were used in the experiment. For each concentration of gum 4, 6 and 8 numbers of passes were applied and graphically observed their stability kinetics' and microscopic view of particle distribution in emulsion system was observed for each sample through microscope. It was found that at $15 \%$ gum concentration and 6 passes was best one and showed most stability than others.
\end{abstract}

Keywords: Gum concentration, Homogenization, Emulsion development, Emulsion stability

\section{Introduction}

Many natural and processed foods consist either partly or wholly as emulsions or have been in an emulsified state at some time during their production; such foods include milk, cream, butter, margarine, fruit beverages, soups, cake batters, sauces, desserts, salad cream, ice cream, and coffee whitener (Dickinson, 1992; Swaisgood, 1996). Emulsion usually consists of at least two immiscible liquid phases one of which is dispersed as globules in the other liquid phase stabilized by a third substance called emulsifying agent. The common liquid phases are aqueous phase and oil phase. Aqueous phase consists of water and different gums as hydrocolloids, and oil phase consists of usually citrus oil based with weighting agent, brominated vegetable-oil, ester gum, sucrose acetate iso-butyrate, bees-wax etc (McClements, 2005). Another important ingredient of emulsion is emulsifier, which stabilizes an emulsion by increasing its kinetic stability. Research revealed that one of the essential molecular features of hydrocolloids was the ability to act as emulsifying agents and emulsion stabilizing agents. Though most hydrocolloids can act as stabilizers (stabilizing agents) of oil-in-water emulsions, only few can act as emulsifiers (emulsifying agents) (Dickinson, 1993; Friberg, 2004). Now-a-days the food industry relies more and more on ready to use food ingredients. This is done to simplify the production and reduce the production cost as much as possible. In Bangladesh there are many soft drinks, cookie, ice cream and bread industries, which use large amount of food grade emulsion for their production. But most of the industries have to depend on imported emulsion to fulfill their requirement due to unavailability of locally developed emulsion. Keeping the above views in mind attempt has been taken to develop a formulation of orange emulsion applying gum arabic as emulsifying agents. The objectives of the study were i) To assess the effect of hydrocolloids as emulsifying agents; ii) To assess the effect of homogenization on emulsion stability.

\section{Materials and Methods}

Orange oil, orange flavor, citric acid, sodium benzoate, gum arabic were collected from market and high pressure homogenizer, microscope, balance were used for this experiment.

\section{Sample preparation}

The standard formulation for the preparation of orange emulsion is given below:

\begin{tabular}{|l|l|}
\hline Ingredient & Amount \\
\hline Orange oil & $10 \%$ \\
\hline Gum arabic & $10-20 \%$ \\
\hline Citric acid & 0.3 \\
\hline Flavour & $1 \%$ \\
\hline Colour & $1 \%$ \\
\hline Sodium benzoate & $0.1 \%$ \\
\hline Distilled water & $67.6-77.6$ \\
\hline
\end{tabular}

* http://www.apv.com 
Before going to carry out each trial oil, water, gum, flavor, color, citric acid, sodium benzoate were mixed properly according to the formulation. After mixing, the solution was kept at room temperature at undisturbed condition for half an hour. Then it was ready for homogenization.

\section{Gum concentration of emulsion}

Gum Arabic, which has dual functions as stabilizer and emulsifier, was used as different concentration of $10 \%, 15 \%$ and $20 \%$. For each concentration, specific amount of gum Arabic was weighed and taken in a pot then water was added to the pot and kept for $1.5-2 \mathrm{hr}$ for wetting of gum. Then the gum solution was filtered through filtering cloth to remove undesirable impurities. Then this solution was ready for mixing with other ingredients and homogenization.

\section{Homogenization of droplet size}

The pre-mixed samples were homogenized for 2, 4, 6, and 8 passes at 1000 psi. At first, hopper of homogenizer was filled with sample then the machine was run. The automation of machine was done by using pipe to the out late. It was calculated that to complete one pass it is necessary $26 \mathrm{sec}$ for $0.5 \mathrm{~L}$ samples. For maintaining pass accurately stop watch was used from starting to stop the machine.

\section{Analysis}

To assess gum effect and homogenization effect stability kinetics' and particle size distribution were used. Particle distribution in emulsion system was observed for each sample through microscope.

\section{Stability study}

For stability studies, homogenized emulsion was stored in plastic tube at room temperature $\left(25^{\circ} \mathrm{C}-27^{\circ} \mathrm{C}\right)$. The total height of homogenized emulsion was measured with a measuring scale. During storage the loss of height was observed and reading was taken on specific storage interval. Percent stability of the samples was calculated as follows:

$\%$ Stability $=\frac{\text { Original height of sample }- \text { Separation height }}{\text { Original height of sample }} \times 100$

\section{Results and Discussion}

\section{Effect of gum (emulsifier) concentration on the stability of emulsion}

A good quality emulsion is kinetically stable for a reasonable period of time. A good quality emulsion could be made by preventing the droplets from the merging of droplets together formed during homogenization. This is achieved by having a sufficiently high concentration of emulsifiers present during the homogenization process.

To assess the effect of emulsifier on the stability of emulsion, three gum concentrations were used and the stability kinetics of emulsion was measured and plotted in Fig. 1.

As shown in Fig. 1, 15\% gum concentration showed better stability than that of emulsion containing $10 \%$ and $20 \%$ gum concentration. Just after 1st day instability exhibited both in the emulsion containing $10 \%$ and $20 \%$ gum. Between them, $20 \%$ showed extreme instability than that of $10 \%$ concentration. However, emulsion developed from $15 \%$ gum concentration also lost stability slightly. 
Practically, emulsifier adsorbs to the surface of the droplets during homogenization, by forming a protective membrane which prevent them from coming close enough together to coalesce (Walstra 1983, 1996a). Droplets formed during 6 passes might better protected at $15 \%$ gum concentration than that of at $10 \%$ and $20 \%$. The $10 \%$ gum concentration might be too low to form a protective membrane to prevent the droplets to come close. On the other hand $20 \%$ concentration might too high concentration to accommodate the droplets in emulsion system.

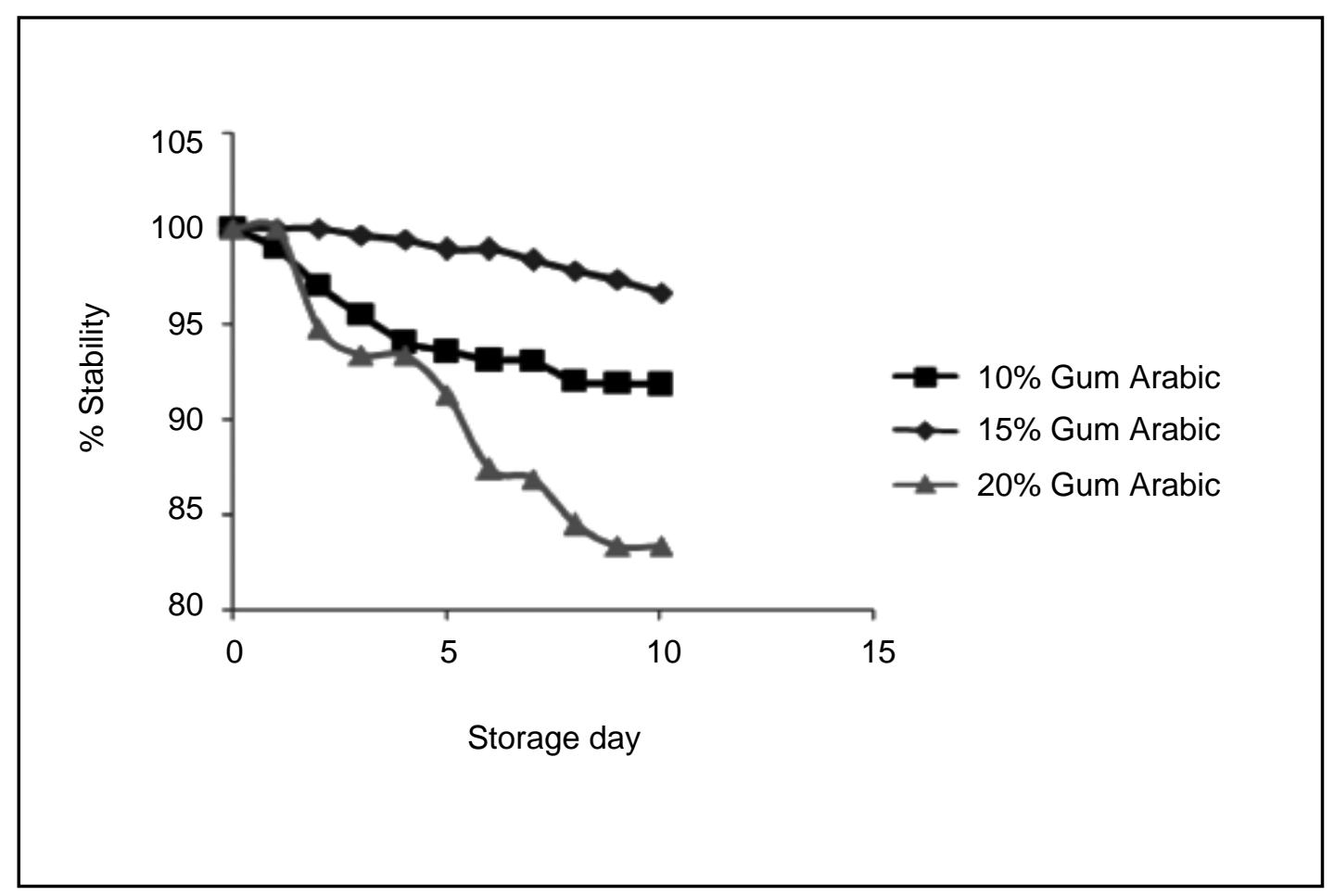

Fig. 1. \% Stability kinetics' of emulsion for 6 passes

As shown in Fig. 2, stability of emulsion containing $10 \%$ gum Arabic exhibited better stability than $15 \%$ and $20 \%$ gum concentration at 8 passes. Instability started just after $1^{\text {st }}$ day of formulation of emulsion in case of $15 \%$ gum. On the other hand, in case of $20 \%$ gum concentration instability started from $2^{\text {nd }}$ day of formulation.

Here in case of $10 \%$ gum due to increase of pass no particle size become uniform and particles are evenly distributed. But in case $15 \%$ and $20 \%$ gum concentrations with increasing gum percentage increase solute content, during homogenization produced temperature relatively higher in $20 \%$ gum containing emulsion than $15 \%$ and $10 \%$ gum containing emulsion. In case of $15 \%$ gum concentration produced temperature is higher than $10 \%$ gum concentration.

\section{Homogenization effect on the stability of emulsion}

Fig. 3 shows that stability of emulsion system containing $10 \%$ gum at 4,6 and 8 passes. Emulsion produced by applying 8 passes is relatively stable than emulsion produced by applying 4 and 6 passes. In case of 8 passes there might uniform particle size and particle distribution even in emulsion system than 6 and 4 passes. In case of 4 passes, instability occur rapidly after $1^{\text {st }}$ day. On the other hand, in case of 6 passes emulsion is more stable than emulsion of 4 passes. 


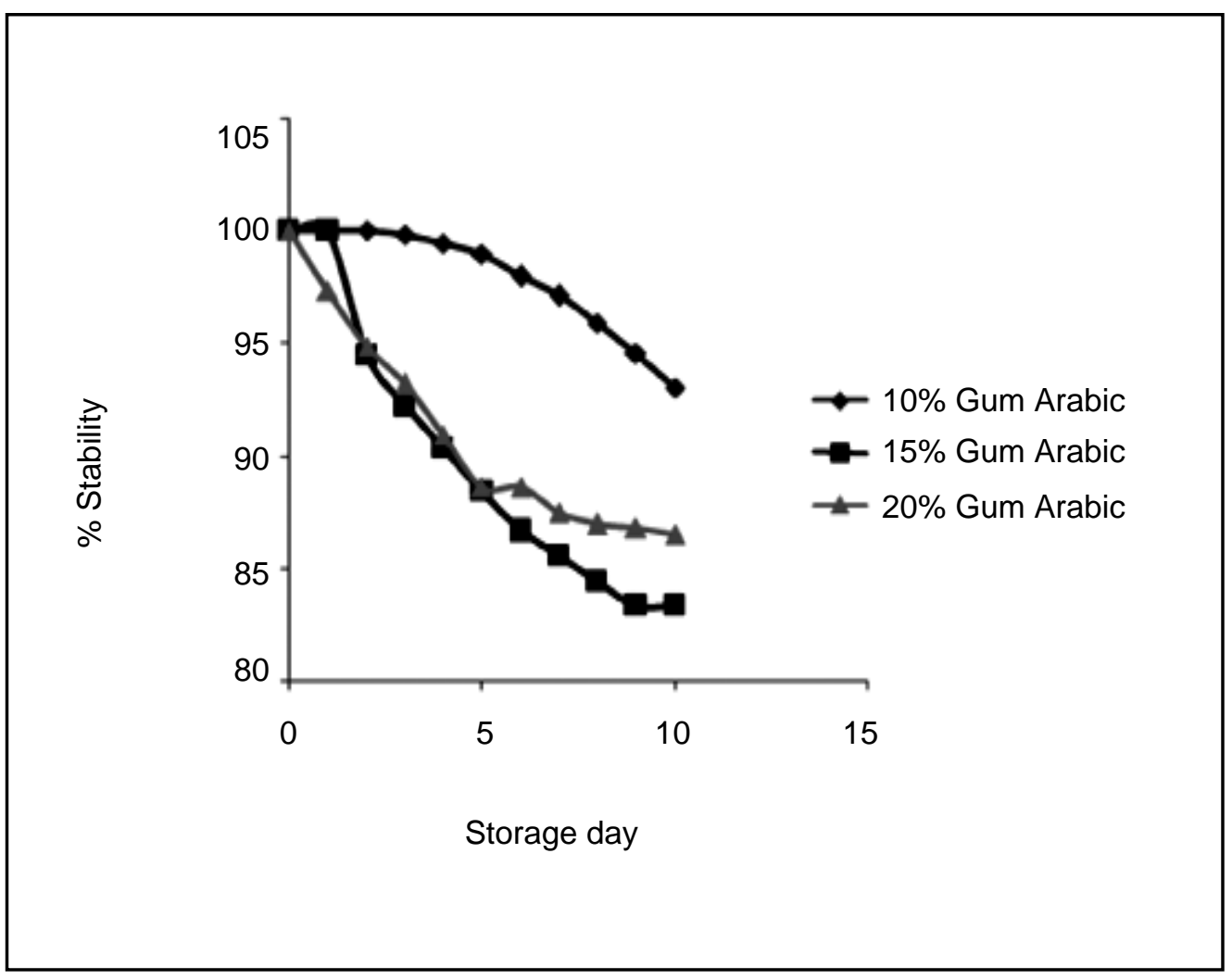

Fig. 2. \% Stability kinetics' of emulsion for 8 passes

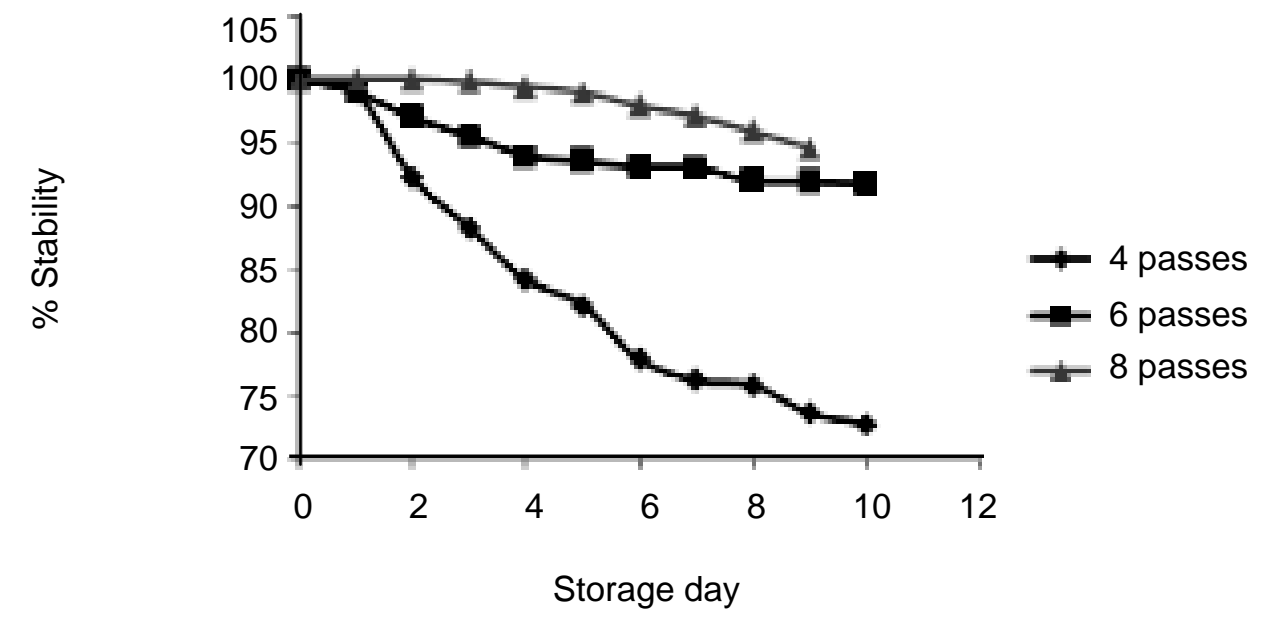

Fig. 3. \% Stability kinetics' of emulsion for $10 \%$ Gum Arabic at different passes 
Fig. 4 shows the stability of emulsion containing 15\%gum and at applying 6 and 8 passes. It is found that the emulsion produce by applying 6 passes is more stable than that of emulsion produce by applying 8 passes. In case of 8 passes, instability started after 1st day and it occur rapidly. This might occur due to adverse storage condition.

Fig. 5 shows that stability of emulsion of $20 \%$ gum concentration and for 6 and 8 passes. Emulsion produced by applying 6 passes is more stable than emulsion produced by applying 8 passes. Instability started just after $1^{\text {st }}$ day of formulation in case of 6 passes and in case of 8 passes instability exhibit from $2^{\text {nd }}$ day. For both cases, $20 \%$ gum concentration is found relatively high gum concentration than $10 \%$ and $15 \%$ gum. Incase case of 8 passes, instability might exhibit due to high solute content and since temperature of product increase with increasing homogenization effect (passes).

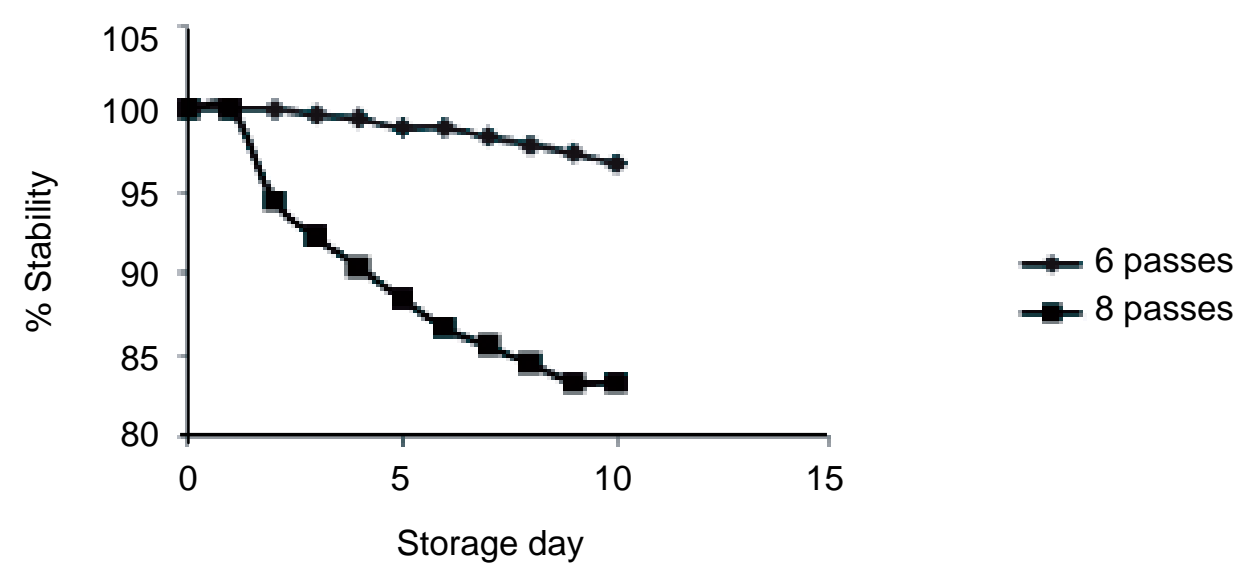

Fig. 4. \% Stability kinetics' of emulsion for $15 \%$ Gum Arabic at different passes

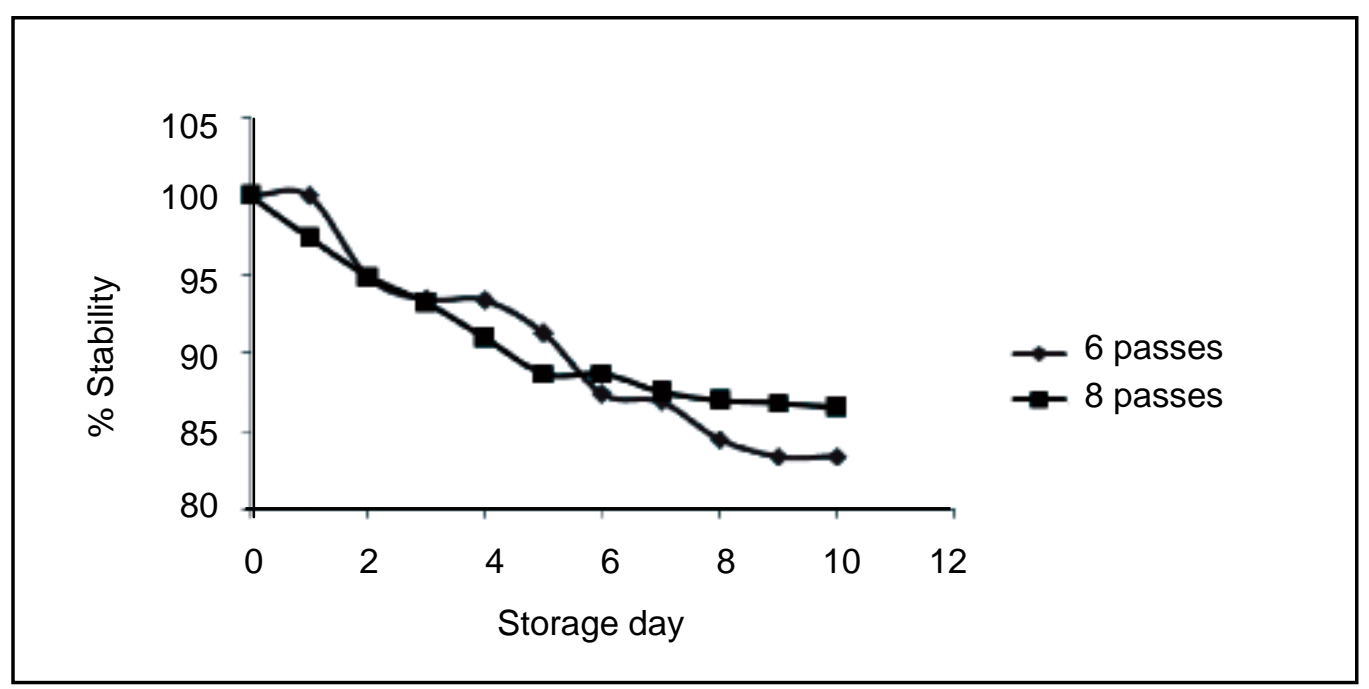

Fig. 5. \% Stability kinetics' of emulsion for $20 \%$ Gum Arabic at different passes 


\section{References}

McClements, D.J., Povey, M.J.W. and Dickinson, E. 1993. Absorption and velocity dispersion due to crystallization and melting of emulsion droplets. Ultrasonics, 31, 443.

Swaisgood, H.E. 1996. Characteristics of milk, in Food Chemistry, 3rd ed., Fennema, G.R., Ed., Marcel Dekker, New York, chap. 14.

Dickinson, E. 1989. A model of a concentrated dispersion exhibiting bridging flocculation and depletion flocculation. Journal of Colloid and Interface Science, 132, 274.

Dickinson, E. 1992. Introduction to Food Colloids. Oxford University Press, Oxford.

Walstra, P. 1996a. Emulsion stability, in Encyclopedia of Emulsion Technology. Becher, P., Ed.,Marcel Dekker, New York, Vol. 4 chap. 1.

Walstra, P. 1983. Formation of emulsions, in Encyclopedia of Emulsion Technology. Becher, P., Ed.,Marcel Dekker, New York, Vol. 1, chap. 2 .

D. J. McClements.1997. Food Emulsions. 3rd edition, Marcel Dekker, New York.

Chanamai R., McClements D.J. 2000. Creaming stability of flocculated mono disperse oil -in-water emulsions. J. Colloid Int. Sci., $225,214-218$

Friberg SE, Larsson K, Sjoblom J. 2004. Food Emulsions. 4th ed.

McClements DJ. 2005. Food emulsions: principles, practices, and techniques. Boca Raton: CRC Press. p. 515- 543.

http://www.apv.com/pdf/technicalinfo/PB_Orange_Oil_Emulsions.pdf 